\title{
LA LEXICOGRAFÍA HISPANO-AMERINDIA DEL SIGLO XVI*
}

\author{
Esther Hernández \\ Instituto de Lengua, Literatura y Antropología, CCHS-CSIC
}

\section{RESUMEN}

En este artículo se ofrece un catálogo descriptivo de los vocabularios españoles con las lenguas amerindias que fueron compilados por los misioneros lexicógrafos a lo largo del siglo XVI. Siguiendo un orden cronológico, se da cuenta de todos los que se hicieron y se exponen sus características más importantes, con especial atención a la influencia que en ellos ejerció el Vocabulario español-latino (ca.1495) de Antonio de Nebrija. Se muestra, además, que la mayoría contiene neologismos interesantes para el estudio histórico del léxico del español en América.

Palabras clave: Lexicografia bilingüe; Lingüística misionera; Lenguas indígenas americanas; Influencia del Vocabulario español-latino ca.1495 de Nebrija en América; Español de América.

\section{ABSTRACT}

The present article offers a descriptive catalogue of bilingual vocabularies of Spanish and indigenous languages of America compiled by missionaries lexicographers throughout the $16^{\text {th }}$ century. The vocabularies composed in this period and their main features are analyzed in chronological order, paying special attention to the influence of the Vocabulario español-latino (ca.1495) by Antonio de Nebrija. Finally, it is also shown that most of the vocabularies record neologisms, which are of interest for the historical study of Spanish lexicon in America.

Keywords: Bilingual Lexicography; Missionary Linguistics; Indian Languages of Americas; Influence of Vocabulario español-latino ca.1495 in America; Spanish in America.

\section{INTRODUCCIÓN}

Este estudio pretende ser una contribución a la historia de la lexicografía bilingüe del español con las lenguas indígenas de América. Desde el área de la filología hispánica, las investigaciones en torno a la producción lexicográfica bilingüe del castellano con las

\footnotetext{
* Del proyecto Corpus de vocabularios bilingües iberoamericanos (siglos XVI-XVIII): Tesoro lexicográfico y
} léxico histórico del español de América [HUM2005-01633]. 
lenguas autóctonas americanas han sido escasas hasta el momento, lo que está en contradicción con el volumen de obras que se elaboraron, con su antigüedad y su largo recorrido histórico, así como con su importancia lingüística y sociocultural por ser fuentes del contacto entre lenguas.

Sin duda, los vocabularios bilingües compilados durante el periodo colonial han sido imprescindibles para el conocimiento de las lenguas indígenas americanas, porque en ellos se reunió el léxico, y a menudo también se explicaron diversos aspectos gramaticales, de unas lenguas que hasta la llegada de los misioneros europeos no se habían escrito con caracteres alfabéticos. Sabido es que los frailes fueron quienes crearon las convenciones gráficas para representar los sonidos de unas lenguas que, a medida que avanzaban en su misión evangelizadora, iban haciendo por conocer ${ }^{1}$. Las diversas grafías, creadas en función de los sistemas fonológicos de cada lengua, fueron empleadas con cierta regularidad durante el primer periodo colonial, lo que fue muy útil para la alfabetización, la gramatización, pero también -y de ello trataremos aquí-, para el registro del vocabulario de las distintas lenguas.

En el caso de varias de las lenguas amerindias, la labor gramatical y lexicográfica de los misioneros contribuyó a su conservación y, por lo que respecta a las lenguas consideradas generales como el náhuatl o el quechua, también a su difusión. Gracias a las obras lingüísticas que los misioneros fueron elaborando, se ha obtenido información valiosa que ha hecho posible conocer el estado de estas lenguas durante el periodo colonial.

Pero además de su valor para la lingüística amerindia, los vocabularios bilingües son importantes para la historia de la lingüística hispánica, para la historia de la lexicografía y también para la lexicología histórica española. Estos diccionarios permiten tener acceso al léxico del español en América y, con ello, facilitan el conocimiento de los diversos procesos de cambio léxico y semántico que tuvieron lugar en el sistema de la lengua española.

Dada la variedad de ámbitos geográficos y la diversidad de las lenguas de las que se elaboraron los vocabularios bilingües, enfocaremos el análisis solo en la primera etapa, que abarcaría el siglo XVI. Y abordaremos sobre todo dos aspectos: por un lado, el que afecta al modelo lexicográfico que siguieron los vocabularios más originales o representativos $\mathrm{y}$, por otro, el que concierne a las novedades léxicas que incorporaron respecto de los vocabularios que les precedieron.

\section{ESTADO DE LA CUESTIÓN}

Algunos de los especialistas más reconocidos en el ámbito de lenguas amerindias realizaron una descripción de la historia de la lexicografía de las lenguas indígenas en la obra Wörterbücher. Dictionaries. Dictionnaires: ein internationales Handbuch zur Lexikographie editada por F. J. Hausmann et al. en 1991. En el capítulo XXXI del tercer

\footnotetext{
${ }^{1}$ Un trabajo pionero sobre la lingüística misionera lo constituye el libro de Suárez Roca (1992).
} 
tomo dedicado a la lexicografía específica por lenguas durante el periodo colonial, diversos autores redactaron el análisis descriptivo de la lexicografía del náhuatl (Karttunnen, pp. 2657-2661), de las lenguas mayas (McQuown, pp. 2661-2670), del tupí-guaraní (Dietrich, pp. 2670-2676), del quechua colonial (Mannheim, pp. 2676-2684) y del aimara (Hardmande-Bautista, pp. 2684-2690). Aunque está centrado en la lexicografía desde 1800, el capítulo siguiente presenta, además, estudios específicos de conjunto que abarcan bibliografía anterior: de las lenguas mesoamericanas (Bartholomew, pp. 2697-2700), de las lenguas de los indios del Orinoco y de la zona amazónica (Ritchie Key, pp. 2700-2704), de las lenguas andinas (íd., pp. 2704-2706), de las lenguas del sur de Brasil y de la región del Río de la Plata (Manelis Klein, pp. 2706-2708), y de las lenguas del sur de Sudamérica (íd., pp. 2709-2710). En todos los casos, los autores dieron cuenta de los diccionarios que se hicieron para cada una de las lenguas y proporcionaron la bibliografía más relevante en torno a estudios sobre las mismas.

Con una simple ojeada a las referencias de esta gran obra internacional de lexicografía se aprecia que la bibliografía tiene solamente un enfoque indoamericanista. Es decir, la parte castellana de los vocabularios bilingües no ha sido hasta el momento objeto de atención prioritario de los estudiosos. En este sentido, por parte de la lingüística románica, sucede que los trabajos de conjunto de la lexicografía hispano-amerindia brillan por su ausencia, lo cual contrasta con la existencia desde hace tiempo de monografías específicas dedicadas a la historia de la primera lexicografía bilingüe italo-española (Gallina 1959), hispano-inglesa (Steiner 1970), catalano-castellana (Colón Domènech 1986), etc.

No existe, pues, tradición en el ámbito de los estudios hispánicos de dejar un lugar, dentro de la historia de la lingüística española, para las obras lexicográficas escritas en América. Por ejemplo, en la obra Historiografía de la lingüística en el ámbito hispánico, publicada en 2007, hay un estudio de los inicios de la lexicografía, pero en España (v. Esparza Torres, pp. 231-367). En la misma obra, se dedica un capítulo específico a la lingüística misionera (v. Ridruejo, pp. 435-477), donde se aborda la descripción de algunos vocabularios de la primera época colonial. Desde nuestro punto de vista, no hay razones para excluir la lexicografía producida en el Nuevo Mundo de la lexicografía del español. Siendo estrictos, si se analiza el léxico español y el método lexicográfico empleado en estas obras, se descubre que nada separa la micro ni la macroestructura del diccionario españolfrancés de Palet (1604), pongamos por caso, de la del vocabulario castellano-náhuatl de Molina (1571), por ejemplo. El hecho de que la lexicografía hispano-amerindia posea la finalidad concreta y específica de promover la evangelización en el Nuevo Mundo ha hecho que se incluyan las obras en lo que se ha dado en denominar lingüística misionera.

En efecto, la labor lingüística de los misioneros está siendo reevaluada en su conjunto (Zwartjes 2000: 7), estudiada más que nunca en los últimos años (Esparza Torres 2003) y se puede decir que su descripción y análisis constituye una sección nueva de la lingüística de gran actualidad e interés (Zimmerman 1997: 2005). Pero, así como la bibliografía hispánica sobre lexicografía española va aumentando, la labor lexicográfica de los misioneros en Indias casi no se conoce. En las últimas décadas han sido prioritariamente estudiadas las artes o gramáticas de las lenguas indígenas compuestas por los misioneros (Zimmermann 1997 y Zwartjes 2000). Y puede decirse que el área de investigación de la lingüística misionera, que tiende a reunir la producción lingüística en torno a esta cuestión 
o problema, ha hecho que constituya una sección lingüística nueva. Sin embargo, aunque tal concepción otorga valor y autonomía científica a las obras de los misioneros como un campo de investigación propio, hace que los diccionarios hispano-amerindios queden excluidos de la historia de la lexicografía española.

El conjunto de los vocabularios bilingües coloniales constituye un fondo lexicográfico apenas estudiado, ni siquiera ha sido empleado como fuente de información lingüística para el español; si bien, la mayoría de los diccionarios contiene innovaciones léxicas y lexicográficas respecto de los vocabularios anteriores, como trataremos de mostrar más abajo. Así pues, y teniendo en cuenta que la descripción de la historia de la lexicografía española está también por hacer (Álvarez de Miranda 1995: 188), consideramos que no estaría de más que los diccionarios que se hicieron en América se incluyeran para la descripción de la misma. Como ya queda dicho, hoy día la bibliografía sigue sin considerarlos $^{2}$. Para reclamar un lugar dentro de nuestra lexicografía, conviene tener en cuenta que los diccionarios más importantes, en el sentido de innovadores en el nivel léxico -como los de Molina (1571), Córdova (1578), Alvarado (1593); v. infra 5.3, 5.8 y 5.11-, tienen el castellano como lengua de encabezamiento de las entradas y las correspondencias en la lengua indígena.

Cierto es que hubo interés por los vocabularios hispano-amerindios en los comienzos de los estudios del español americano, pero también lo es el hecho de que no ha habido continuidad en su atención. Así, Amado Alonso, al idear un proyecto en torno a la dialectología hispanoamericana, afirmaba: "vamos a reeditar gramáticas y vocabularios antiguos (época de conquista) de las lenguas indias. Mucho nos dirán sobre el español importado" (apud Guitarte 1966: 82). Sin embargo, sus propósitos no llegaron a buen puerto y los vocabularios bilingües compuestos por los misioneros en la época colonial continúan siendo, insistimos, un fondo documental apenas explorado por la lingüística hispánica. No en vano, H. López Morales (2000: 161), al tratar los diccionarios generales de americanismos, aseguraba: "la historiografía lingüística hispanoamericana es de una debilidad extrema, especialmente en cuanto a diccionarios se refiere".

En su momento planteó su importancia R. Menéndez Pidal (1944: xiv) y recientemente han reclamado el valor lingüístico de estos vocabularios I. Acero (2001), J. M. Lope Blanch (1999) y T. Smith-Stark (2009). En el Prólogo de su Tesoro lexicográfico S. Gili Gaya descartó su inclusión, entre otras razones, porque decía que "nada añaden a los europeos". Por nuestra parte, hemos tenido ocasión de mostrar que muchos de ellos se apoyan en el Vocabulario español-latino (ca. 1495) de Nebrija, al igual que hicieron los vocabularios europeos del momento, pero presentan rasgos léxicos originales (Hernández 2006).

Finalmente, por lo que respecta a la investigación en lexicología histórica de nuestra lengua, hay que decir que en general los vocabularios hispano-amerindios no se han tomado como fuente para la documentación o la datación léxica. Hay alguna excepción, como la del vocabulario de Molina (1571), que se espigó para la redacción del Diccionario Histórico de

\footnotetext{
${ }^{2}$ V. las colaboraciones del monográfico editado por M. Campos Souto, R. Cotelo García y J. I. Pérez Pascual (2007), Historia de la lexicografía española, y también los trabajos de I. Ahumada (2000) o G. Haensch (2000), así como el Homenaje (2003) a este investigador alemán.
} 
la Real Academia Española -comenzado en 1947 y publicado entre 1960-1996-, aunque solo se papeletizaron las entradas de la primera parte (castellano-nahua), sin incluir el léxico contenido en las definiciones de la segunda (nahua-castellana). Ello quizá fue debido a que se pudo utilizar la edición de 1944 de Cultura Hispánica (Molina 1944 [1571]). Es decir, a nuestro juicio, pudo ser determinante la dificultad de localizar las obras lexicográficas hispano-amerindias o de disponer de ediciones de fácil acceso. No son, de hecho, demasiadas las nuevas ediciones de los diccionarios e, incluso, algunos permanecen inéditos (cfr. Solana, ca.1580 [5.10]). Y sucede también que sus reediciones son muy raras, difíciles de conseguir o, lo que puede resultar filológicamente desacertado, que modernicen ortográficamente el texto. De todas estas cuestiones trataremos en el apartado siguiente.

\section{Problemas de localización de los Vocabularios}

La lexicografía bilingüe hispano-amerindia es bastante rica, pues existe una numerosa colección de vocabularios bilingües escritos por los misioneros europeos a lo largo del siglo XVI. Estas obras lexicográficas, hasta ahora, no se han reunido, enumerado o descrito en una obra o catálogo conjunto.

Sus autores fueron europeos, casi todos españoles, con la excepción de fray Francisco de Alvarado que nació en México; eran hombres generalmente muy cultivados, que pertenecían a las distintas órdenes religiosas, sobre todo a las de los franciscanos y dominicos.

Sabido es que, después de la invención de la imprenta, en Europa proliferaron los estudios descriptivos sobre las lenguas vulgares. La confección de obras lexicográficas tenía como una de sus principales misiones servir de instrumento para los viajeros y comerciantes. En América, la función que vinieron a desempeñar fue la de ser herramienta para la evangelización. Sus destinatarios o usuarios fueron, por consiguiente, los propios frailes, quienes los utilizaban para la producción o descodificación de la lengua de los indígenas, siempre con el propósito último de entenderse con ellos para cristianizarlos.

Reunir todos los diccionarios que compusieron los misioneros es una labor ardua, sobre todo por las dificultades que entraña la localización actual de las obras. No obstante, procuraremos describir o tratar el mayor número posible de los vocabularios que se redactaron durante esta primera centuria, con el fin de facilitar el camino de la investigación, con vistas a que pueda ser completada en el futuro. De modo sobresaliente resulta complicada la elaboración de la lista de los que permanecieron manuscritos en su tiempo, como ocurre por ejemplo de modo singular con los vocabularios con las lenguas mayas (Hernández 2009). Sucede también que hay que distinguir, por un lado, los diccionarios de los que se tiene alguna noticia que se compusieron, pero cuyo paradero es desconocido, se han perdido o sencillamente nunca llegaron a existir realmente. Por otro lado, como es lógico, están los vocabularios que han llegado a nuestros días y que están localizados en las bibliotecas o en las distintas instituciones de Europa o América.

Abundan las obras bio-bibliográficas de las distintas órdenes religiosas, las obras de los grandes bibliófilos y, sobre todo, son de gran utilidad los catálogos de Viñaza (1977 
[1892]) y el más moderno de BICRES I (1994). En el primero, con buen criterio se distinguen en partes diferentes las "obras en que está consignada la fecha de su impresión, composición ó copia" de las "obras que carecen de fecha determinada, ó de las que solamente se tiene noticia de que se compusieron". El segundo presenta las referencias por riguroso orden cronológico, lo que resulta muy cómodo al investigador.

Asimismo, para saber cuántos diccionarios se hicieron, hay que contar con los datos que proporcionan los historiadores de la época, que daban cuenta de las obras que escribían los misioneros, si bien puede ocurrir que recojan diccionarios cuyo paradero actual sea desconocido o se hayan perdido. Este es el caso de un vocabulario en lengua náhuatl, supuestamente escrito por fray Francisco Jiménez, del que trató fray Gerónimo de Mendieta (1870 [ca. 1596]: lib. IV, cap. XLIV). Este, a su vez, fue catalogado por Viñaza y por BICRES I, pero, en nuestra opinión, no se deberían albergar esperanzas para su hallazgo. Como el de Jiménez hay otros casos; así, Mendieta también afirmaba que fray Andrés de Olmos había compuesto vocabularios con las lenguas totonaca y guasteca, los cuales nunca han sido hallados. Lo que ha ocurrido es que la bibliografía ha ido acogiendo, siglo tras siglo, referencias de estos historiadores sin que su información haya sido actualizada. Pensamos que, tanto el cronista religioso Mendieta, como los bibliógrafos coetáneos, tendrían noticias de que se habían compuesto determinadas obras, o incluso pudieron haberlas consultado, pero muchas de las mismas no tuvieron la suerte de pasar a la posteridad. Y, aunque puedan darse apariciones inesperadas, parece lógico suponer que las obras mencionadas no lleguen nunca a encontrarse, porque fuesen reutilizadas por los propios compañeros de orden, y sus datos léxicos reciclados o convertidos en un vocabulario distinto.

Disponemos de los catálogos de las distintas bibliotecas y, para gran ventaja nuestra, hoy se pueden consultar en línea muchos fondos, especialmente de las instituciones o bibliotecas norteamericanas, donde fueron a parar bastantes documentos después de la Independencia hispanoamericana y, de modo singular, después de la de México. Por otro lado, meritoria es, sin duda, la labor que ha desempeñado la Fundación Histórica Tavera, que ha procurado reunir las fuentes documentales etnográficas para el estudio de los pueblos indígenas de Iberoamérica (http://lanic.utexas.edu/project/tavera/). No obstante, aunque las bibliotecas facilitan el envío de copias microfilmadas o en formato $p d f$, en ocasiones hay que acudir a las propias bibliotecas porque es preferible revisar también las gramáticas u otras obras de los misioneros (catecismos, doctrinas, etc.) con las que se pudieron editar o encuadernar los vocabularios.

En cuanto a las monografías o a las investigaciones específicas sobre cada uno de los vocabularios, la bibliografía es escasa, salvo los estudios preliminares que se suelen hacer con motivo de las reediciones de algunas obras, en donde lo habitual es ofrecer una visión de conjunto del autor y de la obra. Así pues, salvo excepciones como la del magnífico estudio de F. Karttunen (1995) sobre la lexicografía del náhuatl, no se suelen relacionar los vocabularios con la tradición en la que están situados, ni tampoco se han solido hacer estudios analíticos con criterios léxicos o lexicográficos. En otras palabras, apenas hay estudios de tipo metalexicográfico en torno a los vocabularios hispano-amerindios. 


\section{CRiterio cronológico}

Para ofrecer un panorama de conjunto sobre los vocabularios coloniales del siglo XVI, hemos optado por seguir un sencillo criterio cronológico, tratando algunos aspectos relacionados con la técnica de elaboración de los vocabularios más importantes. La intención no es la de describirlos todos, pero sí mostrar cuáles son los más representativos durante esa centuria. Naturalmente, otros criterios distintos a la cronología podrían ser utilizados para clasificar los vocabularios y serían de no poca utilidad. Así, por ejemplo, se podrían clasificar: por órdenes religiosas, como hizo D. Bolles (2003, en línea) con los vocabularios de las lenguas mayas compuestos por los franciscanos; por área geográfica, como hizo F. Karttunen (1995) con los vocabularios del área mesoamericana; por lenguas, atendiendo a la producción lingüística de cada grupo, como hizo A. Hernández de Portilla (2003); por tipo de vocabulario; por impresor; etc.

Como es lógico, los vocabularios que fueron impresos no plantean dificultades a la hora de elaborar una lista cronológica; pero sí las plantean los manuscritos, dado que no se suele tener seguridad en torno a la fecha en que fueron redactados. Sobre todo, porque la gran mayoría se ha conservado en copias, no en su versión original. Tales copias hechas por los escribanos pueden estar cercanas en el tiempo, como es el caso de los vocabularios, que veremos más abajo, de verbos nahuas de Olmos (ca. 1540 [5.2]), del cakchiquel de Vico (ca. 1555 [5.4]) o del maya yucateco de Solana (ca. 1580 [5.10]). En este sentido, queremos pensar que estas copias no diferirían excesivamente del original, y, en cualquier caso, las pruebas lingüísticas permitirían refutar las fechas propuestas.

\section{LOS VOCABULARIOS BILINGÜES DEL ESPAÑOL CON LAS LENGUAS AUTÓCTONAS DE AMÉRICA DEL SIGLO XVI}

Expondremos aquí algunas características de los diccionarios redactados en el siglo XVI: ciertos detalles de sus peculiaridades físicas, su direccionalidad, el modelo que siguen (si es que siguen alguno), el paradero de la obra, la bibliografía más relevante, etc. De manera especial, veremos si la primera lexicografía americana se ajusta en sus técnicas y principios a la tradición lexicográfica que comenzó con el Vocabulario español-latino (ca. 1495) de Antonio de Nebrija (en adelante, VEL), citado por algunos autores en los prólogos a sus obras. En este sentido, ya S. Gili Gaya (1947: viii) afirmaba: "Nebrija, reducido y adaptado a las necesidades de la catequesis y de la vida práctica, es también la base de los vocabularios compuestos por los misioneros en las lenguas indígenas de América y de las islas del Pacífico". De ello trataremos en los epígrafes que siguen.

El análisis abarcará: (i) tres vocabularios con el náhuatl, el ms. Ayer 1478 (5.1), el ms. atribuido a Olmos 1547 (5.2) y las dos ediciones de Molina 1555 y 1571 (5.3); (ii) dos vocabularios con la lengua tarasca, el de Gilberti 1559 (5.5) y el de Lagunas 1574 (5.7); (iii) dos vocabularios con el quechua, el de Santo Tomás de 1560 (5.6) y el Anónimo, más conocido por el nombre de su impresor Antonio Ricardo 1586 (5.11); (iv) un vocabulario con la lengua zapoteca, el de Córdova 1578 (5.8); (e) un vocabulario con la lengua mixteca, el de Alvarado 1593 (5.13); (v) dos vocabularios con la lengua cakchiquel, atribuidos a 
Vico ca. 1555 (5.4) y a Alonso ca.1578 (5.9) y (v) dos vocabularios con el maya yucateco, el de Solana ca. 1580 (5.10) y el Anónimo Mayathan ca. 1590 (5.12).

\subsection{Ca. 1540.- Vocabulario trilingüe castellano, latino y mexicano, o Ms. Ayer 1478 de la Newberry Library (Chicago). Anónimo.}

El vocabulario depositado en la Newberry Library de Chicago es un repertorio manuscrito, con número 1478, perteneciente a la colección Edward D. Ayer y se conoce como Vocabulario trilingüe, castellano, latino y mexicano, si bien en el título figura lo siguiente: Dictionarium ex hisniensi [sic] in latinum sermonem interprete Aelio Antonio Neprissensi. Lege foeliciter. Aparece consignado en las bibliografías de Viñaza, $\mathrm{n}^{\circ}$ 699, y de BICRES I, n 96.

Este vocabulario es una adaptación o copia literal del Vocabulario español-latino de Nebrija, a la que se añaden glosas o equivalencias en lengua náhuatl. El texto está escrito en su integridad con una letra pulcra y menuda, de la misma mano, y presenta algunos blancos en la parte nahua, que está escrita con letra roja. Se sitúa en la misma tradición lexicográfica que otros trilingües con lenguas románicas; así sucede, por ejemplo, con el vocabulario con el catalán y el siciliano (cfr. Cristóbal Escobar 1520, apud Esparza Torres 1999, n ${ }^{\circ}$ 174). Para M. L. Clayton (1989) el vocabulario trilingüe es una adaptación de la edición del VEL de 1516, con lo que estamos de acuerdo ${ }^{3}$.

Por otro lado, hay discrepancias en cuanto a su autoría y algunos lo han atribuido a fray Bernardino de Sahagún. Tanto F. Karttunen (1995: 78-80) como M. L. Clayton (1989, 2003) han estudiado detenidamente este diccionario, enfocándose en su parte náhuatl. La primera es de la opinión de que "must predate Molina (1555)", porque emplea las mismas convenciones para representar la lengua nahua que el vocabulario de Molina. Sostiene Clayton, en su artículo de 2003, que es un diccionario para ayudar a nahua-hablantes a descodificar el español. Sin entrar ahora en detalles con respecto a sus planteamientos, su hipótesis no deja de ser sorprendente, porque recordemos que la finalidad habitual de los diccionarios es precisamente la inversa, esto es, la de servir como herramienta a los frailes españoles para predicar y confesar a los indios. Lo que nos parece probable es que el autor o coautor de las equivalencias nahuas de este manuscrito fuera un indio de los aventajados aprendices trilingües que colaboraban con los misioneros-lexicógrafos ${ }^{4}$.

\footnotetext{
${ }^{3}$ Es evidente que la edición de G.J. McDonald (1973 [Sevilla, 1516]) ha facilitado la consulta de esta edición. Lo más seguro es que los frailes no dispusieran de ejemplares de la editio princeps, publicada en Sevilla por Juan Varela sino de otras reimpresiones de la misma, acaso las bidireccionales (latín español; español-latín) de 1560, 1514, 1528, 1532, 1533, 1536 y 1540. V. paradero actual de ejemplares en Esparza Torres 1999, nº 159.

${ }^{4}$ Por cuestiones de espacio o, más bien, de coherencia estructural con respecto a los temas abordados en los demás vocabularios, reservamos para otro lugar el análisis de la hipótesis y de las razones argüidas por Clayton para considerar que sus destinatarios fueran los propios hablantes indígenas.
} 


\subsection{Ca. 1547.- Vocabulario de verbos nahuas atribuido a fray Andrés de Olmos.}

De los seis manuscritos que existen del Arte de la lengua mexicana de fray Andrés de Olmos, solo uno tiene el vocabulario: el que conserva la Universidad de Tulane en su "Latin American Library" con signatura 497.2017 O51. Este vocabulario de verbos nahuas ha permanecido inédito más de cuatro siglos, hasta que lo editó en 1985 la UNAM (Olmos 1935-1985 [ca.1547]). Se trata de un diccionario bidireccional que presenta primero las entradas de verbos nahuas con las correspondencias en castellano, seguida de la parte inversa. Entre otras razones, su valor estriba en ser la primera lista de palabras nahuas original que se conserva y en presentar un estado primitivo de esta lengua, aún poco hispanizada según Sullivan (su editora primera). En cuanto a la lengua castellana, el hecho de que esté manuscrito, como es natural, da valor a las grafías como indicios de fenómenos orales y singulariza esta obra por cuanto que se aparta de los diccionarios nahuas posteriores que, estando impresos, presentan un estado de lengua más regularizado.

En el manuscrito, el arte contiene 288 folios y, desde el 260r, empieza el vocabulario; este cuenta, por lo tanto, con 63 folios y está dedicado exclusivamente a los verbos nahuas. Estos folios, del 210 al 260, no están en el arte que se conserva en la Biblioteca Nacional de España (en adelante BNE), el cual, por otro lado, fue editado con un espléndido estudio preliminar por M. y A. León-Portilla (Olmos 1993 [1547]). El vocabulario de verbos es muy interesante y no parece estar apoyado en una tradición anterior. No obstante, en el Arte Olmos aseguraba que "sere reprehensible si en todo no siguiré la orden del arte de Antonio". Probablemente, para hacer esta gramática del náhuatl -la primera que se publicó en el Nuevo Mundo-, se basaría en las Introduciones latinas de Nebrija (1996 [ca. 1488]) (Esparza Torres 2007a). Recordemos que éstas constituyen un ejemplo del carácter lexicográfico que se da a la gramática, dado que ofrece continuas informaciones de tipo léxico. En otro lugar, el mismo M. Á. Esparza Torres (1999: 249) afirmaba: "con Nebrija, gramática y diccionario sobrepasan la complementariedad pues se alcanza una interdependencia entre los dos componentes".

El procedimiento mediante el cual Olmos confeccionaría su vocabulario debió de consistir en hacer primero un listado de verbos o nociones nahuas; a continuación, daría sencillamente la vuelta a la lista de verbos nahuas, para elaborar, a partir de la misma, la parte con las entradas castellanas. Esta táctica la hemos deducido tras informatizar el texto completo y ver la estricta simetría de ambas partes (Hernández 2005). Por otro lado, es un vocabulario concebido desde la lengua indígena, lo que se advierte en muchas definiciones o entradas en las que hay una traducción literal; por ejemplo, se comprueba en frases como "andar bageando con el coraçon", cuya estructura semántica es extraña al castellano.

En el $V$ Congreso Internacional de Lingüística Misionera celebrado en Mérida (Yucatán) en 2007, se presentó una comunicación en la que se planteaban nuevas dudas sobre la autoría de Olmos para este vocabulario, tras el riguroso análisis del náhuatl del manuscrito (v. Dakin, próxima aparición). 


\subsection{5 y 1571.- Vocabulario en lengua castellana y mexicana y Vocabulario en lengua castellana y mexicana, y mexicana y castellana, ambos de fray Alonso de Molina.}

El vocabulario del castellano con la lengua náhuatl de Molina de 1555 fue el primer diccionario que se imprimió en el Nuevo Mundo. En 1571 salió otra edición, en la que su autor amplió considerablemente el número de las entradas castellanas y a la que añadió la parte con las entradas nahuas.

Puede decirse que la labor lexicográfica que realizó el franciscano fray Alonso de Molina con el náhuatl clásico es excepcional y que, en gran medida, nunca ha sido superada, de ahí que la bibliografía en torno a su obra no sea escasa, habiendo aumentado sustancialmente en los últimos años, y no solo en lo que respecta a estudios sobre la lengua náhuatl (Karttunen 1995: 81-82, 83-85), sino también con especial atención a la parte hispánica del diccionario (v., entre otros, Galeote 1993, 2001; Hernández 1993, 1996a, 1996b, 1999, 2000, 2001; Lope Blanch 1999b; Romero Rangel 2006a, 2006b) Por ello, no nos detendremos en este vocabulario, optando por atender a otros que han sido tratados con menor atención.

De modo escueto, hay que señalar que, Molina, basándose en $V E L$, concretamente en la edición de 1516, elaboró un diccionario original. En efecto, el Vocabulario en lengua mexicana contiene léxico patrimonial y de procedencia indígena perfectamente aprovechable para los estudios en torno a la lexicología y la lexicografía históricas. Pero además, el diccionario de Molina ha tenido una gran repercusión porque constituyó el punto de partida de la lexicografía bilingüe en Mesoamérica y en él se basaron otros misioneros, no solo de la Nueva España, como veremos a continuación, sino también de los misioneros que viajaron al Pacífico (García Medall 2007). Por otro lado, en un interesante estudio basado en una gran base de datos del náhuatl clásico, se ha cuestionado que la parte náhuatl sea realmente representativa de esta lengua en el momento en el que Molina lo compuso (v. Thouvenot, próxima aparición).

Podemos hallar ejemplares de la edición de 1555 y de la de 1571 en la mayoría de las grandes bibliotecas europeas y americanas (BNE, Biblioteca Nacional de Francia [en adelante BNF], British Library [BL], Congress Library [CL], Biblioteca Nacional de México [BNM], etc.).

\subsection{Ca. 1555.- Vocabulario cakchiquel y castellano atribuido a fray Domingo de Vico.}

En el manuscrito conservado en la BNF aparece el título siguiente:

Vocabulario de la lengua cakchiquel con advertencia de los vocablos de las lenguas quiché y tzutohil, se trasladó de la obra compuesta por el Ilmo. Padre el venerable Fr. Domingo de Vico.

Es un vocabulario unidireccional, esto es, solo tiene entradas en la lengua maya cakchiquel y no hay ninguna noticia antigua de que el dominico fray Domingo de Vico escribiera también una parte con las entradas en castellano. Se trata del vocabulario 
localizado más antiguo del área lingüística maya y se estructura en forma de artículos en los que la lengua castellana aparece como metalengua definidora. Así, a continuación de la equivalencia castellana, aparecen frases en cakchiquel y su correspondiente traducción al castellano, con indicaciones gramaticales sobre la lengua aborigen. Sigue, pues, en este sentido, la tradición habitual de los vocabularios en los que se complementan las indicaciones gramaticales y léxicas (Esparza Torres 1999: 249). Una descripción pormenorizada de las características de este vocabulario puede encontrarse en C. BredtKriszat y U. Holl (1997: 175-192), así como en A. Hernández de León-Portilla (2003: 32) y N. A. McQuown (1991: 2670). Lo recogen los repertorios bibliográficos (Viñaza, nº 830; BICRES I, $\mathrm{n}^{\circ} 133$. V. estudio de los indigenismos léxicos contenidos en su parte castellana (Hernández 2008a).

\subsection{9.- Vocabulario de la lengua tarasca y castellana, y castellana y tarasca de fray Matutino Gilberti.}

Entre la edición de 1555 y la de 1571 del vocabulario de fray Alonso de Molina se imprimió el vocabulario con la lengua tarasca de su compañero de orden franciscana fray Maturino de Gilberti. Se conserva un ejemplar original de la primera edición en la BNM, donde se registran los siguientes datos materiales de este diccionario: Gilberti, Maturino, 1498-1585. Vocabulario en lengua de Mechuacan compuesto por el reverendo padre Fray Maturino Gilberty. México: Juan Pablos, 1559 /87, [1], 180, [1] h. ; 4 (21 cm.).

Llama la atención el hecho de que este diccionario bilingüe y bidireccional empiece por la parte con la lengua tarasca o purépecha. En cuanto a la parte con las entradas castellanas, ésta es una adaptación o una copia literal de la nomenclatura vocabulario de Molina de 1555, inclusive en las erratas (cfr. la entrada bramar el torro [sic]). Más interesante resulta, por tanto, la parte tarasco-hispana en donde encontramos 23 indigenismos en las definiciones castellanas, adoptados en distintos grados de adaptación fonética y de integración semántica. Se trata de los vocablos siguientes: cacles, maíz, tianguez, maguey, cacao, tamales, canoa, nahuatlato, auacate, guayaba, ocotalocote, ají, sabana, tamemes, petate, xicaras, mastlatl, maztil, petaca, coa, andumuqua, vanita, xacal y tomatl. Asimismo, en algunos artículos del vocabulario hay definiciones muy literales de la lengua indígena, como "*anochecerme llegando", "dormir sobre el coraçón”, "meter en la boca un trago de agua", "estar el páxaro asentado encima del ramito" o "adelantarse a hablar más que el que empeçó de hablar atajándolo". Estas frases inapropiadas formal o semánticamente en castellano evidencian que esta parte de la obra está predominantemente concebida desde la lengua indígena. Por otro lado, el problema de las palabras compuestas pertenecientes a las lenguas indígenas de tipo aglutinante, como el náhuatl o el tarasco, no fue fácil de resolver por los misioneros. De ahí, quizá, esas traducciones literales de la lengua indígena, en las que se combinan palabras de modo inadecuado en castellano y que resultan opacas semánticamente para el hispanohablante.

La primera parte del vocabulario de Gilberti tiene aproximadamente la mitad de entradas que la segunda, la que pertenece a la tradición nebrisense y que fue seguida en Mesoamérica inicialmente por Molina 1555, 1571. Asimismo, su autor pone en práctica la concepción según la cual la gramática y el léxico están interrelacionados en las obras, pues 
incluso en una definición apunta "[...] Lo demás hallaras en el modus dicendi del arte del principio". La bibliografía sobre la obra de Gilberti es abundante (Martínez Baracs 1997), el vocabulario ha sido objeto de ediciones modernas (Gilberti 1901, 1989, 1997 [1559]) y en el Colegio de Michoacán (México) se lleva a cabo un proyecto de edición de sus obras completas (ProyectoGilberti: v. http://www.colmich.edu.mx/docencia/cet/ colectivos/gilbertini.htm). V. también I. Acero Durántez (1996-1997 [1999]).

\subsection{0.- Vocabulario castellano-quichua de fray Domingo de Santo Tomás.}

Del Lexicon, o Vocabulario de la lengua general del Perv, compuesto por el fray Domingo de Santo Tomás, de la orden de Santo Domingo, impreso en Valladolid por Francisco Fernández de Córdova, en 1560, se ha dicho que es de un valor incalculable para la antropología, la etnografía y la lingüística andinas (Moreno Fernández 1994: 79). Sin embargo, desde el punto de vista del español, es un vocabulario que sigue muy de cerca el $V E L$ de Nebrija y, en este sentido, es poco original.

La lectura atenta del texto castellano nos descubre que las entradas no están planteadas desde el punto de vista indígena y, en la parte quechua-castellana, no se hallan tampoco rasgos que hagan pensar en que está escrito desde una perspectiva indígena. No ocurre, por tanto, como en los diccionarios mesoamericanos vistos más arriba, que presentan entradas y definiciones prolijas, en las que, para la traducción, se desatan morfológicamente los elementos de la composición, con objeto de aproximarla al mundo semántico o a la concepción indígena. Antes bien, en el vocabulario de Santo Tomás no hay ruptura con las estructuras semánticas de la lengua española y, desde el plano léxico, apenas contiene indigenismos. Sorprende, por ejemplo, que se refiera a la pimienta de las Indias, en vez de emplear el antillanismo ají, ya muy usual en el español americano de la época, o que no emplee el quechuismo ucho. No obstante, hay que señalar como dato léxico significativo que documenta el quechuismo papa, que en otras variedades del castellano comúnmente se conoce con la variante patata; palabra que, a su vez, ha pasado a otras lenguas de cultura a través del castellano, como el francés, inglés, etc. (Friederici 1960: s.v.).

Quizás haya contribuido a dichas peculiaridades el hecho de que sea el único diccionario bilingüe con lenguas indígenas americanas de todo el siglo XVI que se imprime en España. Ello es, además, evidente en cuanto a su aspecto físico o material, pues es un libro con formato más pequeño del que suele ser habitual. V. datos bibliográfícos en BICRES I, no 419 y M. Marsá Vilá (2007: 352, 109), así como el trabajo de J. C. Huisa (2006).

\subsection{4.- Diccionario de la lengua tarasca de fray Baptista [Bravo de] Lagunas.}

En el comienzo del vocabulario de Lagunas figura lo siguiente:

Aquí comiença lo más substancial del Vocabulario de Michuacán, hecho y recopilado por fray Juan Baptista de Lagunas de la orden del seráfico padre sant Francisco, y podrase llamar Dictionarito porque el autor (para más provecho de los estudiantes) sigue en el orden y modo del Ambrosio Calepino. 
En las primeras líneas encontramos, pues, una alusión a la fuente en la que dice estar basado, al aludir al diccionario europeo políglota de Ambrosio Calepino.

Lagunas elaboró un diccionario que quizá debería llamarse etimológico, donde consignaba los morfemas radicales de la lengua purépecha que sirven de base a la formación de palabras complejas. Hemos comprobado, por otro lado, que los diccionarios de la lengua de Mechuacán o purépecha hasta ahora vistos (Gilberti 1559 y Lagunas 1574) se asemejan en cuanto a que elaboran un listado de raíces de la lengua indígena, pero Lagunas no parece que copie a Gilberti; además, los dos repertorios tienen una planta completamente diferente. El de Lagunas es un diccionario con mucha digresión, que contiene abundantes referencias a motivos religiosos, lo que entroncaría con la tradición lexicográfica medieval cuasi-enciclopédica de confección de diccionarios. Así mismo, es bien manifiesto el esfuerzo del autor por hacerse entender o resultar didáctico. Con todo, creemos que sería interesante comparar las definiciones de las raíces de los verbos de Gilberti y las de Lagunas para ver su parentesco y filiación. Sin duda, la informatización del texto que lleva a cabo el antes mencionado Proyecto Gilberti hará posible comprobarlo de modo riguroso.

La primera edición del diccionario de Lagunas es muy rara, pero puede encontrarse un ejemplar original en la Biblioteca del Congreso en Washington. Por otro lado, hay reediciones modernas (Lagunas 1890 y 1983).

\subsection{8.- Vocabulario de la lengua castellana y zapoteca de fray Juan de Córdova.}

El Vocabulario de la lengua çapoteca de fray Juan de Córdova es unidireccional, pues solo presenta la parte castellano-zapoteca. La lectura detenida de sus entradas hace pensar que su autor utilizó el diccionario de Molina; pero también empleó el de Nebrija, según hemos comprobado al cotejar entradas de ambos repertorios. Resulta evidente que Córdova utilizó el diccionario de Molina, especialmente en su edición de 1571, por la identidad, entre otros, de los lemas burdel o rameria, o burlar. Córdova también presenta las incorporaciones léxicas que Molina 1571 introdujo como novedades respecto de la nomenclatura del vocabulario nebrisense. Se aparta de Molina 1571 en que suele incluir en el cuerpo de la definición abundantes especificaciones morfológicas o semánticas, y también en que contiene algunos nombres propios -normalmente relacionados con fiestas o motivos religiosos-. Por otro lado, está claro que utilizó el VEL de Nebrija, pues incluye entradas como aburar, acevadarse la bestia, aguatocho (andalucismo léxico) y adunarse, las cuales Molina había suprimido al confeccionar el suyo del náhuatl. Pero además, el vocabulario de la lengua zapoteca no solo incluye las novedades de Molina sino que presenta otras entradas propias, entre otras, aguadija y bacilar. Estas novedades le confieren un carácter original y debido a ello es una obra que ha sido objeto de varios estudios específicos (Smith Stark 1998, 2003).

Hay un ejemplar original de la primera edición en la BNF y una edición facsímil de 1987, pero sin estudio preliminar (Córdova 1987 [1578]). 


\subsection{Ca. 1578.- Vocabulario de la lengua castellana $y$ cakchiquel chi (probablemente) de fray Juan Alonso.}

El Vocabulario en lengua castellana y [guate]malteca que se llama Cak chequel chi está manuscrito. De él, hay diversas copias en varias instituciones, según BICRES I: "BNP, ms américain 7 \& 14; Princeton Univ. Library, ms. Garret 226; Washington Library of Congress, ms. Cortés 120". Por nuestro lado, hemos encontrado otra copia en la Lilly Library, en Bloomington, sin que sepamos aún si es idéntica a las demás.

Pues bien, tras cotejar la copia incompleta conservada en la biblioteca Lilly, así como las láminas del ms. Garret 266 colgadas en la Red -que en esta institución se atribuye a Félix Solano (v. http://libweb5.princeton.edu/mssimages/Garrett-Gates\%20Mesoamerican/ garrettgatesmeso226-f1r.jpg)-, comprobamos que las entradas castellanas de este vocabulario son una copia literal de las entradas del vocabulario de Molina 1571. Se trata, por consiguiente, de una adaptación con muy pocas diferencias léxicas, y a la que se añadirían después las equivalencias en la lengua cakchiquel. Estas correspondencias cakchiqueles sirvieron a otros autores para componer sus propios diccionarios con esta lengua maya. Así sucedió con el vocabulario de fray Thomas de Coto, de 1650, que lo cita como fuente (Hernández 2008b).

De este vocabulario hay una edición moderna a cargo de O. Smailus (1989).

\subsection{Ca. 1580.- Vocabulario de lengua española y maya yucateco atribuido a fray Francisco de la Solana.}

La Hispanic Society of America de Nueva York conserva un diccionario manuscrito con el título de Vocabulario muy copioso en lengua española y maya de Yucatán, en cuya portadilla aparece como autor fray Francisco de la Solana, como lugar de composición Mérida y la fecha de 1580 . Este vocabulario permanece inédito y de él se conserva otra copia, muy parecida, en la biblioteca John Carter en Brown, Providence (EE.UU.). En un estudio específico que realizamos de este manuscrito, dedujimos que esta copia se había realizado con posterioridad ${ }^{5}$ (Hernández 2008c). Mostramos en él, así mismo, que este vocabulario atribuido a fray Alonso de la Solana se sitúa en la tradición lexicográfica nebrisense y es original en diversos aspectos léxicos. Así pues, la parte con las entradas castellanas siguió la estela del nebrisense y también parece que su autor consultó el vocabulario de su compañero de orden franciscana, fray Alonso de Molina.

\subsection{6.- Vocabulario de la lengua castellana y de la lengua quichua del impresor Antonio Ricardo. Anónimo.}

En la BNE, con la signatura R/9166, hay un ejemplar original del libro

\footnotetext{
${ }^{5}$ Lo presentamos en una comunicación para el II Congreso Internacional de Lexicografía Hispánica, celebrado en Alicante del 19 al 23 de septiembre de 2006.
} 
Arte, y vocabulario en la lengva general del Perv llamada Quichua, y en la lengua Española. El mas copioso y elegante que hasta agora se ha impreso. En los Reyes. Por Antonio Ricardo. Año de M.D.LXXXVI. Lima, Antonio Ricardo.

En torno a la autoría de este vocabulario anónimo, conocido como el "Vocabulario de Antonio Ricardo" hay diversas hipótesis (Rivet y Créqui-Montfort 1956, Lope Blanch 1990: 43, Escobar 1951) Es un diccionario bidireccional que, en su nomenclatura castellana, no parece que siga al que le precedió de la lengua quechua, esto es, al vocabulario de Santo Tomás. Entre otras razones, y en oposición a éste, en el de Antonio Ricardo la presencia indígena es bien manifiesta en el léxico, pues podemos documentar en él, entre otros, los siguientes indigenismos léxicos: el quechuismo coca o la voz aborigen de Panamá chicha, pero también antillanismos como aji o cabuya. Incluso, en el nivel semántico, se percibe la influencia indígena en algunas equivalencias castellanas ("exclamación del que alaba una cosa pequeñita"). En él, es interesante también la fraseología ("andar a tienta paredes"). Asimismo, presenta nombres propios, como “Atawallpa, Inka rey". Sin duda, este repertorio contiene novedades léxicas perfectamente aprovechables para la lexicología histórica del español. V. Aguilar Pérez, ed. (1970).

\subsection{Ca. 1590. Vocabulario en lengua castellana y maya yucateco, Anónimo Mayathan.}

El manuscrito del vocabulario hispano-maya de Mayathan, que se encuentra en Viena, en la Academia Nacional Austriaca ("Codex vindobonensis" S. N. 3833), tiene las entradas en castellano y las equivalencias en la lengua maya de Yucatán. Ha sido editado en versiones facsimilares por Mengin (1972) y por Acuña (1993). El vocabulario de Mayathan no sigue la nomenclatura de Nebrija de manera evidente, pero parte de su caudal léxico subyace en el texto (Hernández 2009c). Tiene una estructura semejante a los repertorios anteriores a Nebrija, con equivalencias fraseológicas y abundantes datos enciclopédicos, relativos a la orden franciscana. Hay varias hipótesis sobre su autoría (Bolles 2003 [en línea]).

\subsection{3.- Vocabulario de la lengua castellana y mixteca de fray Francisco de Alvarado.}

De los vocabularios impresos en el siglo XVI en la Nueva España, el Vocabulario en lengua mixteca de Francisco Alvarado fue el más tardío (México, 1593). Ello permitió a su autor basarse en el modelo del Vocabulario español-latino de Nebrija en las versiones publicadas hasta esa fecha, así como utilizar los vocabularios novohispanos más importantes ya impresos, como son el del náhuatl de Molina $(1555,1571)$ y el del zapoteco de Córdova (1578), según hemos tenido ocasión de comprobar. Lo más interesante de este vocabulario de la lengua mixteca es que brinda novedades lexicográficas respecto a sus predecesores y permite adelantar la fecha de registro de voces como amusgar o cairel, entre otras, si tenemos en cuenta el Tesoro lexicográfico de S. Gili Gaya, el Nuevo Tesoro Lexicográfico de la Lengua Española de la RAE y el más reciente Nuevo Tesoro Lexicográfico del Español dirigido por L. Nieto Jiménez y M. Alvar Ezquerra. Por otro lado, en muchas entradas de este diccionario hallamos ampliaciones morfológicas o 
semánticas del lexema base respecto de los anteriores, que lo hacen muy interesante para estudios específicos de lingüística histórica del español americano.

Este impreso no es de fácil localización; por ejemplo, no lo encontramos en la BNE. Hay, sin embargo, un ejemplar en la Biblioteca Central del Instituto Nacional de Antropología e Historia (INAH); otro en la BNF; copia fotográfica de Gates del ejemplar de la BNF; en la CL en Washington (cfr. Jiménez Moreno, en Alvarado 1962 [1593]). Hay, que sepamos, solo una edición moderna (ibidem), difícil de encontrar también.

\section{RECAPITULACIÓN}

Hemos realizado una breve exposición del elenco de todos los vocabularios hispanoamerindios que se conservan hoy y que fueron compilados por misioneros durante el siglo XVI. Sin embargo, por razones diversas no hemos descrito algunos de ellos. Así, el vocabulario castellano-tzeldal y tzeldal-castellano de fray Domingo de Ara (ca. 1571) no se ha tratado porque, de la parte con las entradas castellanas, solo hay una copia algo posterior y reducida, aunque someramente podamos asegurar que se basa en el $V E L$ y que contiene algunas novedades léxicas. Tampoco hemos considerado el vocabulario del maya yucatecocastellano de fray Antonio de Ciudad Real (finales del siglo XVI) porque corresponde a las postrimerías del siglo XVI y a los comienzos de la siguiente centuria (v. Ciudad Real [fin. del siglo XVI]). Asimismo, hemos descartado la inclusión de vocabulario anónimo del castellano-tzotzil, por su insegura datación (cfr. Anónimo 1988 [prob. finales del siglo XVI]). Lamentablemente, no nos ha llegado a tiempo una copia del Diccionario grande de la lengua de Michoacán, diccionario bidireccional español-tarasco/tarasco-español que conserva la Biblioteca Latinoamericana de la Universidad de Tulane, y del que hay una edición facsímil de J. B. Warren 1991.

Hemos constatado la influencia del Vocabulario español-latino de Nebrija en los inicios y en el desarrollo de la lexicografía hispano-amerindia durante el siglo XVI, confirmando, pues, las palabras de Karttunen (1995: 87): "without his works in hand, the missionary grammarians/lexicographers in New Spain would no foundation upon with to build". En efecto, algunos autores se fundaron en el VEL (Molina 1555 y 1571, Anónimo Mayathan ca. 1590), mientras que otros hicieron una adaptación del vocabulario de Molina de 1555 $\left(\right.$ Gilberti $\left.1559^{6}\right)$. En un vocabulario se copiaron las entradas del vocabulario de Molina 1571 (Alonso ca. 1578), mientras otros se inspiraron al tiempo en Molina 1571 y en el VEL (Córdova 1578, Solana ca. 1580 y Alvarado 1593). Así mismo, hemos visto cómo los dos vocabularios con el quechua (Santo Tomás 1560 y Anónimo Antonio Ricardo 1586) siguieron también la tradición nebrisense, aunque carecen de conexión alguna con los mesoamericanos. En definitiva -con la excepción hecha por el vocabulario de Olmos 1547, compuesto a partir de una lista de verbos nahuas- los vocabularios que tienen como lengua

\footnotetext{
${ }^{6}$ Aunque no entra en el periodo cronológico que abarca este estudio, también el vocabulario trilingüe castellano, náhuatl y otomí de Urbano 1605 es una copia literal de la nomenclatura castellana del vocabulario de Molina 1555 .
} 
de partida la castellana, y que son la gran mayoría de los que se compusieron durante el siglo XVI, se basaron en el vocabulario nebrisense directamente o también, los de la Nueva España, a través del vocabulario de Molina.

Por otra parte, y basándose en varios vocabularios (ms. de NL, Molina 1555, Gilberti 1559, Molina 1571, Córdova 1578, Alvarado 1593 -y también Urbano 1605-), Karttunnen aseguraba que estos intercalan "new entries of their own" (l.c.). Por nuestra parte, hemos ampliado esta indagación, haciendo por abarcar todos los vocabularios bilingües con lenguas indígenas que se han conservado del siglo XVI. En la mayoría de los mismos, se confirma el hecho de que sus autores no se limitaron a copiar las entradas del vocabulario nebrisense, sino que las ampliaron, las redujeron o las modificaron para adecuarlas al mundo semántico impuesto por la nueva visión de las lenguas americanas o por la nueva realidad de la geografía americana. Por tanto, habría que matizar las palabras de S. Gili Gaya (1947: viii), aquellas en las que decía que: "los vocabularios españoles en lenguas indígenas americanas [...] los que hemos podido examinar contienen escaso léxico español y nada añaden a los diccionarios europeos, especialmente a Nebrija [...]". Seguramente, fueron las insalvables dificultades de localización y acceso a otros vocabularios que debieron encontrar Gili Gaya y su equipo, las que motivarían su postura a la hora de incluir o no los vocabularios hispano-amerindios en su Tesoro lexicográfico.

En definitiva, hemos tratado de dar ejemplos de los neologismos que incorporaban los distintos vocabularios y hemos mostrado que pueden ser fuentes para el conocimiento del léxico español. Incluso, en los repertorios en los que el español es lengua de llegada (Vico ca. 1555 o Lagunas 1574), sus materiales también pueden ser fuentes léxicas del español, útiles para conocer datos de la evolución del español en América.

\section{REFERENCIAS BIBLIOGRÁFICAS.}

\section{Fuentes primarias}

AlVARADO, fray F. (1962 [1593]). Vocabulario en lengua mixteca, reproducción facsimilar con un estudio de W. Jiménez Moreno y un apéndice con un Vocabulario sacado del Arte en lengua mixteca de fray Antonio de los Reyes, México, Instituto Nacional Indigenista e Instituto Nacional de Antropología e Historia.

ANÓNIMO [= RICARDO, A.] (1586). Arte, y vocabulario en la lengva general del Perv llamada Quichua, y en la lengua Española. El mas copioso y elegante que hasta agora se ha impreso. En los Reyes. Por Antonio Ricardo. Año de M.D.LXXXVI, Lima, A. Ricardo.

ANÓNIMO (1988 [prob. finales del siglo XVI]). The great tzotzil dictionary of Santo Domingo Zinacantán, R. M. Laughlin y J. B. Haviland (eds.), Washington, Smithsonian Institution.

ARA, D. de (1986 [ca. 1555]). Bocabulario de lengua tzeldal según el Orden de Copanabastla, M. Humberto Ruz (ed.), México, Universidad Nacional Autónoma de México. 
ARA, D. de (ca. 1555). Vocabulario de la lengua española y tzeldal, en línea http://www.famsi.org/research/mltdp/item $185 /$

Ciudad Real, A. de (1984 [fines s. XVI]). Calepino maya de Motul, R. Acuña (ed.), México, UNAM.

CÓRDOVA, fray J. de (1987 [1578]). Vocabulario en lengua çapoteca, ed. facsimilar, México, Ediciones Toledo.

DICCIONARIO grande de la lengua de Michoacán, v. WARREN.

GiLberti, M. (1901 [1559]). Diccionario de la lengua tarasca o de Michoacán, A. Peñafiel (ed.), México, Tipografía de la Oficina Imp. de Estampillas.

[GILBERTI, M. (1989 [1559])] = J. B. WARREN, introducción histórica y reproducción facsimilar de Vocabulario en lengua de Mechuacan de Maturino Gilberto, Morelia, Fimax.

Gilberti, M. (1997 [1559]). Vocabulario en lengua de Mechuacán, transcripción paleográfica A. Jacinto Zavala, revisión paleográfica C. Martínez y J. B. Warren, Zamora / México D. F., Colegio de Michoacán / Fideicomiso Teixidor.

Lagunas, J. B. de (1890 [1574]). Arte y diccionario tarascos, Nicolás León (ed.), Morelia, Imp. y Lit. en la Escuela de Artes.

LAGunAS, J. B. de (1983 [1574]). Arte y dictionario: con otras obras en lengua michuacana, compuesto por Juan Baptista de Lagunas, introducción histórica con apéndice documental y preparación fotográfica del texto de J. B. Warren, Morelia / Michoacán / México, Fimax.

MENDIETA, fray G. de (1870 [ca. 1596]). Historia eclesiástica indiana. Obra escrita a fines del siglo XVI, J. García Icazbalceta (ed.), México, Antigua Librería.

MolinA, fray A. de (2001 [1555]). Aquí comiença vn vocabulario en la lengua castellana y mexicana, M. Galeote (ed.), Málaga, Universidad de Málaga.

MolinA, fray A. de (1994 [1571]). Vocabulario en lengua castellana y mexicana, Madrid, Cultura Hispánica.

MolinA, fray A. de (2001 [1571]). Vocabulario en lengua castellana y mexicana, edición facsímil y estudio de E. Hernández, Madrid, Agencia Española de Cooperación Internacional, Biblioteca Nacional.

NebriJA, E. A. de (1989 [ca. 1495]). Vocabulario español-latino, facsímil de la primera edición, patrocinado por la Asociación de Amigos de la Real Academia Española, Madrid, RAE.

NEBRIJA, E. A. de (1973 [1516]). Vocabulario de romance en latín, transcripción crítica de la edición revisada por el autor (Sevilla, 1516) con una introducción de G. J. McDonald, Madrid, Castalia.

NEBRIJA, E. A. de (1996 [ca. 1488]). Introduciones latinas contrapuesto el romance al latín, M. Á. Esparza y R. Sarmiento (eds.), Madrid, Fundación Antonio de Nebrija, SGEL. 
Olmos, fray A. de (1935-1985 [ca. 1547]). Arte de la lengua mexicana y vocabulario, introducción, advertencias, paleografía y apéndices de T. D. Sullivan; R. Acuña (ed.), México, Universidad Nacional Autónoma de México.

Olmos, fray A. de (1993 [1547]). Arte de la lengua mexicana, edición, estudio introductorio, transliteración y notas A. y M. León-Portilla, Madrid, Cultura Hispánica.

PAlet, J. (1604). Diccionario muy copioso de la lengua española y francesa [...] Dictionaire tres ample de la langue espagnole et française, París, M. Guillemot.

Rincón, A. del (1595). Arte mexicana, reproducido en Obras clásicas sobre la lengua náhuatl, A. Hernández de León-Portilla (comp.), Fundación Histórica Tavera, Serie IX, vol. 8, Fuentes lingüísticas indígenas, CD Rom.

SAnto Tomás, D. de (1560). Lexicón, o Vocabulario de la lengua general del Perv, Valladolid, F. Fernández de Córdova.

SANTO TOMÁs, D. de (1951 [1560]). Lexicón, o vocabulario de la lengua general del Perú, compuesto por el Maestro Fray Domingo de S. Thomas, prólogo de R. Porras Barrenechea, ed. facsímil, Lima, Universidad Nacional Mayor de San Marcos, Instituto de Historia.

Urbano, A. (1990[1605]). Arte breve de la lengua otomí y vocabulario trilingüe: español, náhuatl, otomí, R. Acuña (ed.), México, Universidad Nacional Autónoma de México.

\section{Fuentes secundarias}

ACERO DURÁNTEZ, I. (1996-1997). "En los comienzos de la lingüística mesoamericana: el influjo de Alonso de Molina en la obra de Maturino Gilberti”. Anuario de Lingüística Hispánica 12-13/1, 199-211.

ACERo DurÁnTEZ, I. (1999). "Notas para la historia de la lexicografía americana: a propósito del Vocabulario de Diego González Holguín”. Actas del XI Congreso Internacional de la Asociación de Lingüística y Filología de la América Latina, J. A. Samper Padilla y M. Troya Déniz (coords.), Las Palmas de Gran Canaria, Servicio de Publicaciones de la Universidad de Las Palmas de Gran Canaria, t. III, 1793-1805.

AgUilar PÉREZ, R. (1970). Gramática quechua y vocabularios. Adaptación de la primera edición de la obra de Antonio Ricardo "Arte y vocabvlario en la lengva general del Perv llamada quichua, y en la lengua española”, Lima, 1586, Lima, Universidad Nacional Mayor de San Marcos.

Ahumada, I. (ed.) (2000). Cinco siglos de lexicografía del español, Jaén, Universidad de Jaén.

Álvarez de MirandA, P. (1995). "Hacia una historia de los diccionarios españoles en la Edad Moderna". Bulletin Hispanique 97/1, 187-200.

BICRES I = H.-J. NIEDEREHE (1994). Bibliografia cronológica de la lingüística, la gramática y la lexicografía del español (BICRES). Desde los comienzos hasta el año 1600, Amsterdam, J. Benjamins. 
BREDT-Kriszat C., U. Holl (1997). "Descripción del Vocabulario de la lengua cakchiquel de fray Domingo de Vico". La descripción de las lenguas amerindias en la época colonial, K. Zimmermann (ed.), Madrid, Iberoamericana, 175-192.

Clayton, M. L. (1989). “A trilingual Spanish-latin-nahuatl manuscript dictionary sometimes attributed to fray Bernardino de Sahagún". International Journal of American Linguistics 55/4, 391-416.

Clayton, M. L. (2003). "Evidence for a Native-Speaking Nahuatl Author in the Ayer Vocabulario trilingüe". International Journal of Lexicography, 16/2, 99-119.

Colon Domènech, G. (1986). Panorama de la lexicografia catalana: de les glosses medievals a Pompeu Fabra, Barcelona, Enciclopèdia Catalana.

DAKIN, K. (inédito). "La organización de los verbos en el Vocabulario del Ms. del Arte de Olmos en la Universidad de Tulane". Quinto Congreso Internacional de Lingüística Misionera, Mérida (Yucatán), del 14 al 17 de marzo de 2007.

ESCOBAR RisCO, G. (1951). "Prólogo". Vocabulario y praxis en la lengva general del Perv llamada Quichua, y en la lengua Española, Anónimo ( $1^{a}$ ed. 1586, Lima), Lima, Instituto de Historia, Filosofía y Letras, VII-XX.

ESPARZA TORRES, M. Á. (1999). "Gramática y diccionario en las primeras descripciones del español". Actas del I Congreso Internacional de la Sociedad Española de Historiografía Lingüistica, M. Fernández Rodríguez, F. García Gondar y N. Vázquez Veiga (eds.), Madrid, Arco Libros, 245-256.

EsParza TORRES, M. Á. (2007). "Nebrija y los modelos de los misioneros lingüistas del náhuatl”. Missionary Linguistics III / Lingüistica misionera III. Morphology and Syntax, O. Zwartjes, G. James y E. Ridruejo (eds.), Amsterdam, J. Benjamins, 3-41.

EsParza Torres, M. Á. (2007). "Los inicios de la lexicografía en España”. Historiografía de la lingüistica en el ámbito hispánico. Fundamentos epistemológicos y metodológicos, Madrid, Arco Libros, 231-267.

Esparza Torres, M. Á., E. Battaner Moro, V. Calvo Fernández, A. Álvarez FERNÁNDEZ, S. RODRÍGUEZ BARCIA (2008). Bibliografía temática de historiografía lingüística española (= Romanistik in Geschichte und Gegenwart 17), Hamburgo, H. Buske.

FRIEDERICI, G. (1960). Amerikanistisches Wörterbuch und Hilfswörterbuch für den Amerikanisten, Hamburgo.

GARCíA-MEDALL, J. (2007). "La traducción codificada: Las artes y vocabularios hispanofilipinos (1610-1910)". Hermeneus: Revista de la Facultad de Traducción e Interpretación de Soria 9, 117-144.

GILI GAYA, S. (1947). Tesoro lexicográfico (1492-1726), (A-CH), Madrid, CSIC.

HAENSCH, G. (2000). Textos clásicos sobre la historia de la lexicografía del español de América, Madrid, Biblioteca Nacional de España / Ayuntamiento de Madrid, 1 CD.

Hausmann, F. J. et al. (eds.) (1989-1991). Wörterbücher. Dictionaries. Dictionnaires: ein internationales Handbuch zur Lexicographie, Berlín [etc.], W. de Gruyter. 
HERNÁNDEZ, E. (1996). Vocabulario en lengua castellana y mexicana de fray Alonso de Molina. Estudio de los indigenismos léxicos y registro de voces castellanas internas, Madrid, CSIC.

HERNÁNDEZ, E. (1999). "Algunas particularidades léxicas del primer diccionario americano". Miscelánea léxica en memoria de Conchita Serrano, Madrid, CSIC, 339344.

HeRnÁndeZ, E. (2000). "El Vocabulario náhuatl de Molina frente al Vocabulario de Nebrija". Iberorromania 52, 1-9.

HERNÁNDEZ, E. (2001). "El léxico innovador en el Vocabulario en lengua castellana y mexicana de Molina (México, 1571)". Estudios sobre el español de América, H. Perdiguero y A. Álvarez (eds.), Burgos, Universidad de Burgos, ed. en CD, 730-741.

HERNÁNDEZ, E. (2006). "Influencias de método y concepción entre los vocabularios novohispanos del siglo XVI". América y el diccionario (= Anexos de Revista de Lexicografía 2), M. Campos Souto, F. Córdoba Rodríguez y J. I. Pérez Pascual (eds.), La Coruña, Universidade da Coruña, 63-77.

HERnÁNDEZ, E. (2008a). "Aproximación al Vocabulario de la lengua cakchiquel o guatemalteca de fray Thomás de Coto (ca. 1650) como fuente léxica del español". Bulletin Hispanique 110/1, 319-331.

HERNÁNDEZ, E. (2008b). "Indigenismos en el Vocabulario de la lengua cakchiquel atribuido a fray Domingo de Vico, ms. BNF R.7507'. Revista de Filología Española 88/1, 67-88.

HERNÁNDEZ, E. (2008c). "El vocabulario hispano-maya conservado en la biblioteca 'John Carter Brown' (Codex Indicus 8)". Revista de Lexicografia 14, 111-122.

HERNÁNDEZ, E. (2009). "Vocabularios hispano-mayas del siglo XVI". Missionary Linguistics IV / Lingüística Misionera IV. Lexicography, O. Zwartjes, R. Arzápalo Marín y Th. C. Smith-Stark (eds.), Amsterdam / Filadelfia, J. Benjamins, 129-149.

HeRnÁNDEZ DE LEÓN-PORTILlA, A. (2003). "Las primeras gramáticas mesoamericanas. Algunos rasgos lingüísticos". Historiographia Linguistica 30/1-2, 1-44.

HOMENAJE a Haensch (2003). Lexicografía y Lexicología en Europa y América. Homenaje a Günther Haensch en su 80 aniversario, Madrid, Gredos.

HuisA, J. C. (2006). "Los diccionarios del español peruano: análisis de los conceptos que subyacen a cada uno a partir de sus prólogos". América y el diccionario, M. Campos Souto, F. Córdoba Rodríguez y J. I. Pérez Pascual (eds.), La Coruña, Universidade da Coruña, 79-89.

Lope Blanch, J. M. (1990). Estudios de historia lingüística hispánica, Madrid, Arco Libros.

LOPE Blanch, J. M. (1999). "Americanismos en el Vocabulario de fray Alonso de Molina”. Estudios de lingüística hispánica. Homenaje a María Vaquero, A. Morales et al. (eds.), Editorial de la Universidad de Puerto Rico, 335-347.

LOPE BlanCH, J. M. (2004). "De historiografía lingüística mexicana". De historiografía lingüística e historia de las lenguas, México, Siglo XXI, 21-34. 
LóPez Morales, H. (2000). "Diccionarios generales de americanismos". Cinco siglos de lexicografía del español, I. Ahumada (ed.), Jaén, Universidad de Jaén, 161-176.

MARSÁ VILÁ, M. (2007). Materiales para una historia de la imprenta en Valladolid (siglos XVI y XVII), León, Universidad de Léon.

MARTíNEZ BARACS, R. (1997). "El vocabulario en la lengua de Mechuacan (1559) de fray Maturino Gilberti como fuente de información histórica". Lengua y etnohistoria purépecha. Homenaje a J. Benedict Warren, C. Paredes Martínez (coord.), Morelia, Universidad Michoacana de San Nicolás de Hidalgo, Centro de Investigaciones y Estudios Superiores en Antropología Social, 67-162.

MoReno FERnÁndez, F. (1994). "Antonio de Nebrija y la lexicografía americana del siglo XVI. A propósito del Lexicón de Fray Domingo de Santo Tomás”. Voz y Letra 5/1, 79104.

NIEDEREHE (1994), v. BICRES I

Nieto Jiménez, L., M. Alvar EzQuerRa (dirs.) (2007). Nuevo Tesoro Lexicográfico del Español (siglo XIV-1726), Madrid, Real Academia Española / Arco Libros.

REAL ACADEMIA EsPañola (2001). Nuevo Tesoro Lexicográfico de la Lengua Española, Madrid, Espasa Calpe, 2 DVDs.

ReAl ACADEMia EsPaÑola (1960-). Diccionario histórico de la lengua española, Madrid, Real Academia Española.

RIDRUEJO, E. (2007). "Lingüística misionera". Historiografía de la lingüística en el ámbito hispánico. Fundamentos epistemológicos y metodológicos, Madrid, Arco Libros, 435477.

Rivet, P., G. CRequi-Montfort (1956). Bibliographie des langues aymara et kicua, París, Institut d'Ethnologie.

Romero RANGel, L. (2006). "El quehacer lexicográfico en los Vocabularios de Alonso de Molina”. Actas del VI Congreso Internacional de Historia de la Lengua española, J. L. Girón Alconchel y J. J. de Bustos Tovar (coords.), Madrid, Arco Libros, t. 2, 16611672.

ROMERO RANGEL, L. (2006). "La originalidad del 'Vocabulario castellano-mexicano' (1571) de Alonso de Molina”. América y el diccionario, J. I. Pérez Pascual, F. Córdoba Rodríguez y M. Campos Souto (coords.), La Coruña, Universidade da Coruña, 137-152.

SMAILUS, O. (1989). Vocabulario en lengua castellana y guatemalteca que se llama cakchiquel chi: análisis gramatical y lexicológico del cakchiquel colonial según un antiguo diccionario anónimo, Bibliothèque nationale de Paris-Fond americaine $n{ }^{\circ}$, Hamburgo, Wayasbah, 3 vols.

Smith Stark, T. C. (1998). "Juan de Córdova como lexicógrafo". Guchachi' Reza 58, 213.

SMith StARK, T. C. (2003). "La ortografía del zapoteco en el Vocabulario de Fray Juan de Córdova". Escritura del zapoteco, de sus orígenes a nuestros días, M. A. Romero Frizzi (ed.), México, Porrúa, Centro de Investigaciones y Estudios Superiores en Antropología Social, 173-240. 
SMITH StARK, T. C. (2009). "Lexicography in New Spain (1492-1611)". Missionary Linguistics IV / Lingüística Misionera IV. Lexicography, O. Zwartjes, R. Arzápalo Marín y Th. C. Smith-Stark (eds.), Amsterdam / Filadelfia, J. Benjamins, 3-82.

STEINER, R. J. (1970). Two centuries of spanish and english bilingual lexicography: (15901800), La Haya, Mouton.

SuÁreZ RoCA, J. L. (1992). Lingüistica misionera española, León, Pentalfa.

TESORO lexicográfico, v. GILI GAYA.

THOuvenot, M. (inédito). "Le nahuatl de Molina est-il vraiment du nahuatl?".

VIÑAZA, conde de la [C. Muñoz y Manzano] (1977 [1892]). Bibliografía española de lenguas indígenas de América, Madrid, Sucesores de Rivadeneyra.

WARren, J. B. (1991 [fin. XVI]). El diccionario grande de la lengua de Michoacán, Morelia, Fimax.

ZimmermanN, K. (ed.) (1997). La descripción de las lenguas amerindias en la época colonial, Madrid, Iberoamericana.

ZWARTJeS, O. (2000). Las gramáticas misioneras de tradición hispánica, Amsterdam, Rodopi.

Esther Hernández

esther.hernandez@cchs.csic.es

Instituto de Lengua, Literatura y Antropología

Centro de Ciencias Humanas y Sociales, CSIC

c/Albasanz, 26-28, despacho 1E8

28037 Madrid 